Please cite this article as:

Dell’Era C, Landoni P and Gonzalez SJ (2018).

Investigating the Innovation Impacts of User-Centered and Participatory Strategies adopted by European Living Labs.

International Journal of Innovation Management.

(DOI: 10.1142/S1363919619500488) 


\title{
Investigating the Innovation Impacts of User-Centered and Participatory Strategies adopted by European Living Labs
}

\begin{abstract}
The advantages of innovation strategies that are based on collaboration with users have been demonstrated by several studies, which have highlighted emerging shifts from a User-Centered approach (in which the user is a subject) to a participatory one (in which the user is a partner). The Living Lab methodology, which is a design research methodology aimed at co-creating innovation through the involvement of aware users in a real-life setting, can provide new perspectives in the passage from User-Centered to Participatory Design. In this paper, answers received by 92 Living Labs belonging to the European Network of Living Labs are used to i) investigate the strategies adopted by Living Labs to involve users in their innovation processes and ii) analyze the relationships between strategies and achieved innovation performance outcomes.

The User-Centered Strategy positively impacts all innovation performance outcomes (e.g., Time, Cost, Quality and Go To Market), but only Time performance shows a significant difference between non-adopters and adopters. Observing user behaviors, capturing user insights and receiving user feedback positively impacts the efficiency of innovation projects and allows them to be concluded in a timely manner. The Participatory Strategy shows that adopters are characterized by a significantly higher percentage of projects that are able to reach the market by moving from the research stage to the innovation stage. Practices such as co-design, collaboration through digital platforms, and development of experience prototypes allow for the achievement of better results in terms of quality and consequently, marketability of the project outcome, but reduce the efficiency of the innovation project in terms of time and cost.
\end{abstract}




\section{Introduction}

In the last decade, several scholars have underlined the central role of the user in the innovation process (Almirall and Wareham, 2008; Følstad, 2008; Schuurman et al., 2011; Leminen et al., 2012). Successful design firms such as IDEO, Continuum and Frog pioneered innovation approaches that use emerging approaches such as User-Centered Design (Kelley, 2001; Lojacono and Zaccai 2004), Human-Centered Design (Buchanan, 2001) and more recently Design Thinking (Brown, 2008 and 2009; Martin, 2009). According to these emerging approaches, users not only act as sources of information, but also directly contribute to the innovation process by acting as testers, developers, and even designers. The increasingly relevant role that design-based approaches can play in generating competitive advantages is also demonstrated by recent acquisitions; for example, McKinsey \& Company, a management consulting giant, purchased Lunar, a leading design consulting firm, in May $2015^{1}$. The deal illustrates how central design is to business today and also how design's influence is growing beyond traditionally design-based sectors into the corporate world at large. Indeed, Lunar was known for its work with clients such as Apple, HP, and SanDisk. The progressive shift from UserCentered paradigms (with the user as a subject) to Participatory paradigms (with the user as a partner) requires new methodologies and tools to valorize the contribution provided by users (Sanders and Stappers, 2008; Leminen et al., 2015). The theoretical contribution provided by Bogers et al. (2010) underlines that users can play different roles in the innovation process, yet several questions remain unanswered.

Even if there is not a common and widely recognized definition of Living Labs (Eriksson et al., 2005; Almirall and Wareham, 2008; Kviselius et al., 2009; Schuurman et al., 2011; Tang et al., 2012), Dell'Era and Landoni (2014) argue that the Living Lab methodology can provide new perspectives in the transition from UserCentered to Participatory Design; they define a Living Lab as an example of design research methodology that is aimed at co-creating innovation through the involvement of aware users in a real-life setting. In other words, the Living Lab methodology is based on two primary elements: i) a real-life test and experimentation environment and ii) the users who are aware that they are co-involved in the innovation process. Users can

\footnotetext{
${ }^{1}$ http://www.wired.com/2015/05/consulting-giant-mckinsey-bought-top-design-firm/
} 
act in the Living Lab methodology both as subjects and objects of the innovation process. Users can simply contribute to the Living Lab methodology by expressing their needs and desires (Schuurman et al., 2011), or they can directly shape innovation by acting as testers or co-producers (Riedl et al., 2009).

Even if the Living Lab methodology is rapidly diffusing, as demonstrated by the growth of the European Network of Living Labs (ENoLL, www.openlivinglabs.eu), the literature remains underdeveloped. Whereas several studies have already mapped different forms that Living Labs can assume (Bergvall-Kåreborn et al., 2009; Eriksson et al., 2005; Feurstein et al., 2008; Kallai, 2010), few studies have investigated the relationship between the innovation strategies adopted by Living Labs and the innovation performance outcomes that are achieved.

In this paper, answers received by 92 Living Labs belonging to the European Network of Living Labs (response rate $=29 \%$ ) are used to i) investigate the strategies adopted by Living Labs to involve users in their innovation processes and ii) analyze the relationships between strategies and achieved innovation performance outcomes. The remainder of the paper is divided as follows. Firstly, we summarize the main contributions in the literature about Participatory Design approach and methodologies. We then explain the adopted research methodology and the data. The empirical results are presented and discussed in the fourth section. Finally, we conclude by highlighting the limitations of this study and avenues for future research.

\section{Literature Review}

The open innovation (OI) paradigm is defined as a distributed innovation process that leverages the flow of knowledge crossing company boundaries (Chesbrough and Bogers, 2014). These inflows and outflows are respectively able to accelerate the internal development process and the external exploitation process (Chesbrough, 2003). Engaging the right partners is crucial in open innovation and collaborative processes. Indeed several sources of external knowledge are found in the literature (e.g. users, suppliers, competitors, universities and research centers). Among these sources, the critical role that users can play in the innovation process has been underlined by several scholars (Almirall and Wareham, 2008; Følstad, 2008; Schuurman et al., 2011; Leminen et al., 2012), to the point that we have seen a progressive evolution in the management 
of collaborative innovations involving users over the last two decades: for instance from user-centered design (Kelley, 2001; Lojacono and Zaccai, 2004) to human-centered design (Buchanan, 2001), and from design thinking (Brown, 2008 and 2009; Martin, 2009) to design sprint (Knapp, 2016).

In this context, several scholars underline the importance of the progressive shift from design paradigms based on user-centered approaches to participatory paradigms (Schuler and Namioka, 1993; Muller et al., 1993; Sanders 2002 and 2006). Both in the literature and in practice, there is an increasing interest in methodologies and tools that can support the "participatory mindset" (see Figure 1 for a Map of the most diffused ones). Living Labs, visualized in the bottom-right quadrant, represent one of the newest and less analyzed of such methodologies. In the following paragraphs, we first describe the shift from User-Centered Design to Participatory Design. We then focus on participatory methods, highlighting the peculiarities of the Living Lab methodology among them.

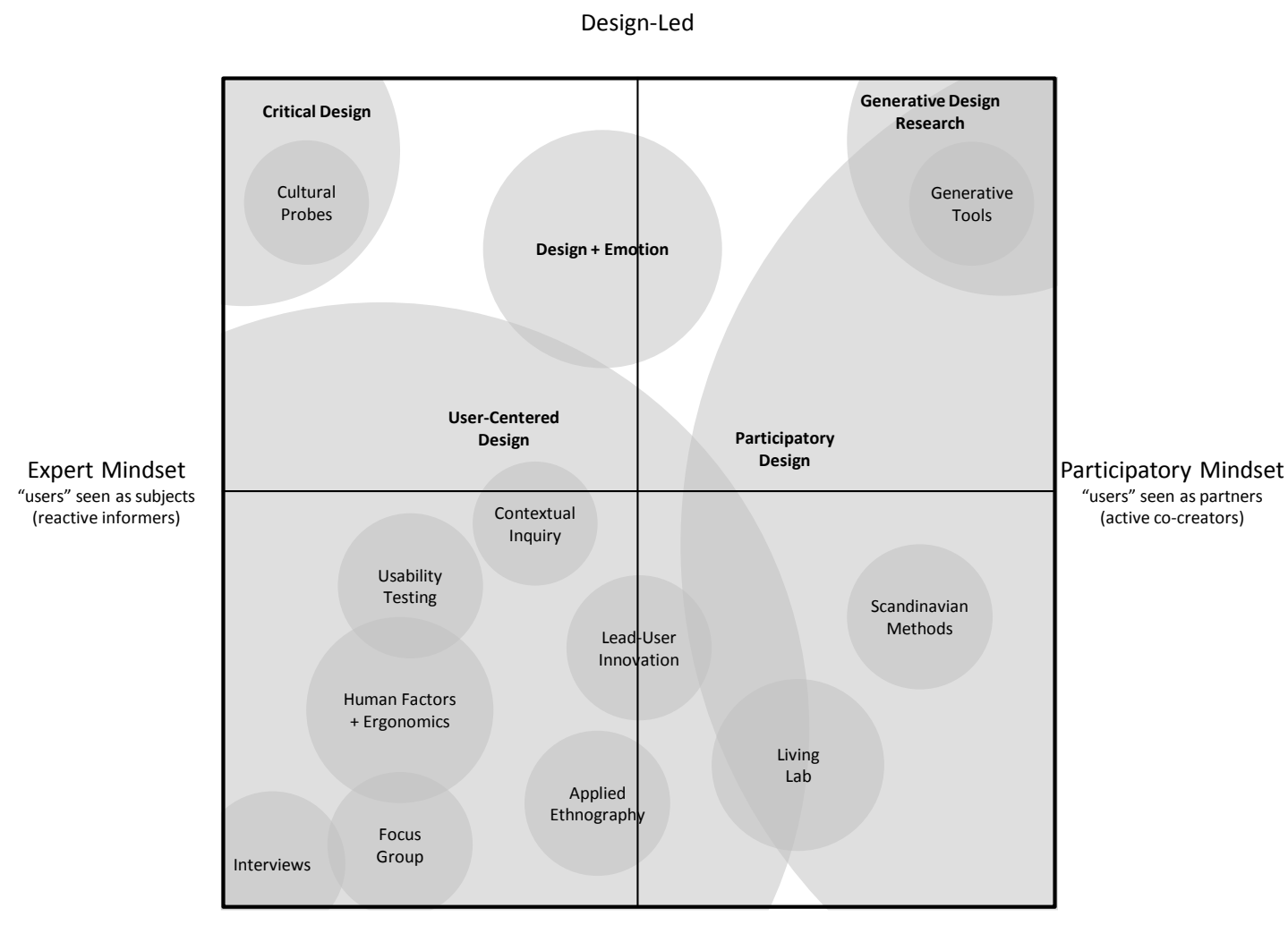

Research-Led

Figure 1: Map of Design Research Methodologies (adapted from Sanders, 2006 and Dell'Era and Landoni, 2014) 
From User-Centered Design to Participatory Design

User-Centered Design (UCD) is a design approach that is focused on users. In this approach, users are located at the center of an interactive process in which information regarding users' needs and preferences is collected and used during the entire process. UCD could also be described as a mindset or design philosophy focusing on the central role of the user in the design process; according to this philosophy, users can be both the objects under study and the main actors to whom the solutions are addressed (Preece, 1993; Leminen et al., 2012; Nyström et al., 2014). From the early 1930s, the New Bauhaus movement of Chicago stimulated a "human-centered" design approach, but the term was not popularized until the mid-1980s when it was used by Donald Norman in his book, The Design of Everyday Things. Norman argues that UCD refers to design that is based on the needs of the user in situations in which the needs of the user dominate the design of the system and that the purpose of the system is to serve the user (Norman, 1986 and 1988).

Later, Karat (1996) described user-centered design as a process in which users or user data are considered to be the criteria for generating ideas and evaluating the quality of a project. User-Centered design is about design for people, taking user input into consideration in order to meet users' needs. The Usability Professionals Associations define UCD an approach that grounds this process in information about the people who will use the product in the future and that focuses on users through the planning, design and development of the product (www.usabilityprofessionals.org). UCD is based on the idea that user information will facilitate an understanding of how people will use a product or a service in the future and that will allow designers to include better features in creating new solutions. It is common that users in UCD processes act as sources of information, documenting their own behavior or testing some products or services and assuming an active role. User-Centered design also supports the idea that early user involvement promotes a more efficient design process, as users will help the designers to select ideas and move forward based on solid insights collected directly from future users. Thus, the interaction between design teams and representative users through the use of different methods will help develop easy-to-use solutions. UserCentered Design is considered the key to product usability because of its multidisciplinary approach and because users are actively involved in improving designers' and researchers' understanding of user needs and task requirements (Mao et al., 2005). UCD represents a shift away from the prevailing notion that the 
capabilities of technology are more important than the needs of the people as well as a shift away from innovations for the sake of the efficiency of technology improvements toward innovation that is created based on the needs of the market (Friess, 2008).

Participatory design (PD), formerly called Cooperative Design, emerged in Scandinavia when designers and users worked together to improve the quality of working environments and to foster democracy in the workplace during the 1970s. Participatory Design might be described as a mindset about designing with users. Participatory design is based on the idea of involving those who will become "users" as full participants of the process from the early stages of ideation to the final implementation when a product or a service is tested and launched into the market. Distinctions are made between levels of participation, depending upon the objectives of designers and researchers, including transmitting information (unidirectional), consultation (bi-directional) or active participation, which is based on a partnership in which all stakeholders actively engage in the debate (Slocum, 2003).

The first Participatory Design conference highlighted the mindset of the PD approach, which is that "people who are affected by a decision or event should have an opportunity to influence it." Potential users are considered those with the most knowledge about what they need. In addition to the levels of interaction between users and researchers, in PD, researchers also recognize the importance of having as many users as possible sharing knowledge and expertise to address complex problems (Czyzewski, et al. 1990; Schuler et al., 1993). The active role of users becomes a critical component in design and decision-making processes to ensure that the designed product or service meets their needs (Slocum, 2003; Sanders, 2006). The importance of actively participating in the process is what distinguishes participatory design from related approaches such as User-Centered Design. PD is not only about conducting research or design work on behalf of users but also about doing this work with them during all phases of the process. Designers and users interact constantly to discuss and evaluate ideas and to facilitate negotiation between the actors so that actors may arrive at an agreement about how to change a solution according to the feedback of the different stakeholders.

Participatory Design results in many approaches and techniques for eliciting user experiences. Some of these techniques are used to enable discussion, especially during the creative phases of the design process (e.g., 
idea generation) and to collect information about user experiences (Sleeswijk Visser et al., 2005). Others are generative techniques (Sanders, 2000) that ask users to make drawings, collages, or maps to express their experiences and to discuss these expressive artifacts with one another. Users are respected as experts about their experience domains, and their contributions make them participatory actors in the design process (Sanders, 2000; Sanders and Stappers, 2008; Sleeswijk Visser et al., 2005; Sanders et al., 2010).

\section{Living labs as a participatory methodology}

The Living Lab methodology can provide new perspectives in the passage from user-centred to Participatory Design. The literature regarding the Living Labs phenomenon is very limited to the point that there is a lack of a widely recognized definition (Kviselius and Andersson, 2009; Tang et al., 2012). There are many definitions of Living Labs, most of which are in agreement about two main features: i) a real-life testing and experimentation environments and ii) the inclusion of users who are aware that they are co-involved in the innovation process (Westerlund and Leminen, 2011; Almirall and Wareham 2008; Leminen et al., 2015; Kviselius and Andersson, 2009; Tang et al., 2012, Bergvall-Kåreborn and Ståhlbröst, 2009). According to the definition proposed by Dell'Era and Landoni (2014), "A Living Lab is a design research methodology aimed at co-creating innovation through the involvement of aware users in a real-life setting." On the one hand, users are involved and aware of the innovation process, as opposed to users studied by applied ethnography (Spradley, 1979, 1999; Kotler and Scott, 1999; Dell'Era and Landoni, 2014). On the other hand, users are not special in terms of skills or knowledge of the technologies as they are during user-lead innovation (Von Hippel, 1986; Dell'Era and Landoni, 2014). Living Labs can take place both in physical spaces or virtual realities characterized by openness and user involvement (Nyström et al., 2014; Westerlund and Leminen, 2011; Pascau and van Lieshout, 2009; Almirall, 2009; Almirall et al., 2012; Leminen et al., 2012). The Living Lab methodology allows an exploration of different categories of users' needs, ranging from observable needs to tacit and latent needs (Dell'Era and Landoni, 2014). In the Living Lab methodology, the shared responsibility for creation results in a co-creative process. However, the role of context is crucial. The designer does not interact directly with the users and leaves the users free to interact with the environment (Dell'Era and Landoni, 2014). 


\section{Research Methodology}

As previously mentioned, the paper aims to i) investigate the strategies adopted by Living Labs in involving users in their innovation processes and ii) analyse the relationships between strategies and achieved innovation performance outcomes. In the following paragraphs, we introduce the conceptual framework and the associated constructs, after which we briefly describe the sample.

\subsection{Conceptual Framework}

In order to explore the first research objective, i.e. the strategies adopted by Living Labs in involving users in their innovation processes, we interpret the Living Lab as a design research methodology aimed at cocreating innovation through the involvement of aware users in a real-life setting; more specifically we investigate two main strategies that Living Labs can adopt: i) users can be involved in the innovation process, observing users' behaviours, capturing insights during the early stages of the project, and asking for feedback during the late stages of the project (User-centred Strategy); ii) users can also participate in the innovation process by co-designing potential solutions, interacting through digital platforms and experimenting with prototypes (Participatory Strategy). In other words while the User-centered Strategy mainly leverages on "What people say" and "What people do", the Participatory Strategy focuses on "What people make" (Sanders, 2002). Explicit needs can be identified by listening to what the customer says, while keeping in mind that the customer reveals only what he wants; consequently, the customer determines the developmental direction of the analysis. However, analysing what the customer does may be insufficient because it underlines only his observable needs and skips an unexplored area related to what the customer knows, feels and dreams. For this reason, to engage users in making innovations and collaborating in design processes can lead to identify and interpret additional desires (Sanders, 2002). The three categories of needs may also be reinterpreted under the temporal horizon (Sanders, 2001): "What people do" mainly underlines the current situation, "What people say" reveals the past and the immediate future, and "What people make" stimulates to investigate the remote past (memory) and the most distant future (dreams) (Sanders, 2001). 
According to these reflections, the User-centred Strategy is conceptualized along three key questions that investigate specific practices:

- Observing users' behaviours: Do you observe the users addressed by the innovation project developed by the Living Lab?

- Capturing users' insights: Do you involve users to capture insights during the early stages of the innovation project developed by the Living Lab?

- Receiving users' feedback: Do you involve users to ask for feedback during the late stages of the innovation project developed by the Living Lab?

Similarly, the Participatory Strategy is conceptualized along three key questions that investigate alternative practices:

- Co-designing with users: Do you co-design potential solutions in collaboration with users during the innovation project developed by the Living Lab?

- Collaborating with users through digital platforms: Do you enable collaboration between users and the Living Lab through digital platforms?

- Enabling users' experience though prototypes: Do you allow users to test and experience prototypes during the innovation project developed by the Living Lab?

In order to investigate the second research objective, i.e. the relationships between the strategies enacted by the Living Labs and the achieved innovation performance outcomes, we could have relied on two literature and practitioner streams of thought: the one focused on the project side, i.e on the innovation process (e.g., Ibbs and Kwak, 2000; Golini et al., 2015) and the one interested in the innovation results, i.e. the (mainly economic) impacts obtained by the product and services being developed such as sales level; net profit; return on sales; return on invested capital (e.g., Robinson, 1998). However, both our focus (on the methodologies) and the object of our study (the Living Labs) suggested to concentrate our efforts on the project side. Indeed our paper is focused on the different impact of the different methodologies that can be used by the living labs, thus on the way in which their projects are conducted. Furthermore our unit of analysis (the living labs) could provide data more on the way in which they have conducted the projects than 
on the results achieved by these projects in the medium to long term. Asking the Living Lab about the economic results of the projects after one or two years would have led to no answers (because of the Living Lab managers ignorance about such developments) or to approximate and difficult to compare answers (difficulty of gathering objective data on the projects long term results and difficulty in comparing qualitative estimates by the Living Labs managers). However a) we acknowledge the limit of our focus only on the project side (and we will further highlight this limit in the conclusion b) we try to gauge at least a part of the economic impact measuring the number of projects that actually resulted in products and services sold in the market. To summarize, we conceptualize the impacts of the user-centred and participatory strategies on innovation performance outcomes according to two main constructs (see Figure 2):

- the capability of achieving the project objectives in terms of expected lead-time, budget and quality (three classic Project Performances) (e.g., Turner, 2009);

- the capability of delivering a solution able to reach the market, i.e. to move from the research and experimentation stage to the innovation stage (we called this performance Transfer Performance, leveraging the parallel with the technology transfer literature and the efforts to transfer academic research results to industry, e.g. Van Looy et al. 2011).

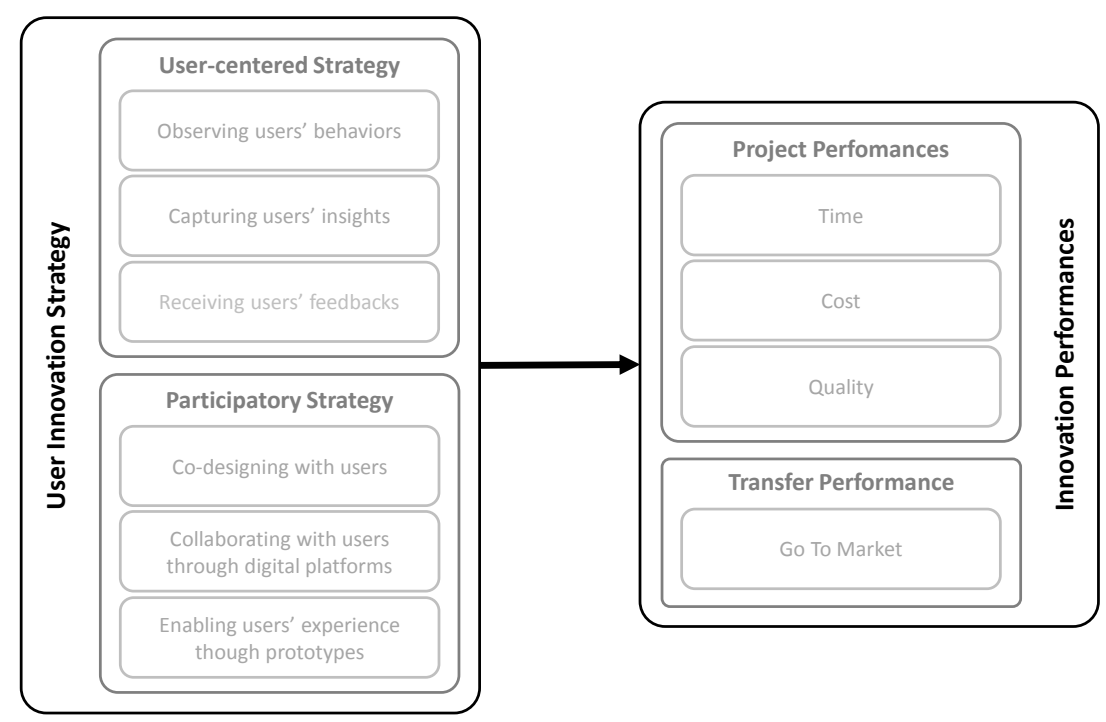

Figure 2: Conceptual framework 


\subsection{Sample Description}

From an empirical point of view, this paper leverages data collected in 2012 through a survey distributed to 320 Living Labs following an endorsement provided by the European Network of Living Labs (ENoLL). ENoLL is the international federation of benchmarked Living Labs in Europe and worldwide. Founded in November 2006 under the auspices of the Finnish European Presidency, the network has grown in 'waves' up to this day. As of 2015, ENoLL had more than 170 active Living Lab members worldwide (395 historically recognized over nine years), including active members in 20 of the 28 EU Member States and two EU candidate countries; it was present in five continents in addition to Europe. Directly, as well as through its active members, ENoLL provides co-creation, user engagement, and test and experimentation facilities targeting innovation in many different domains, such as energy, media, mobility, healthcare, agrifood, etc. We have collected complete answers about the User-centred and Participatory practices from 92 Living Labs (28.75\%) and complete answers about the Project and Transfer performance outcomes from 65 Living Labs (20.31\%). In both cases the answer rate allow us to significantly represent the entire population composed of the 320 Living Labs. More precisely 92 Living Labs belong to six different waves developed by ENoLL before 2012: 6 Living Labs (6.52\%) belonging to Wave 1 (2006), 6 Living Labs (6.52\%) belonging to Wave 2 (2007), 21 Living Labs (22.83\%) belonging to Wave 3 (2008), 20 Living Labs (21.74\%) belonging to Wave 4 (2010), 24 Living Labs (26.09\%) belonging to Wave 5 (2011) and 15 Living Labs (16.30\%) belonging to Wave 6 (2012).

\subsection{Operationalization}

The adoption frequency of all investigated practices is measured according to a Likert scale ranging from 1 to $5(1=$ Never; 2 = Rarely; $3=$ Sometimes; 4 = Very often; 5 = Always $)$. In order to capture the strategic approach adopted by each Living Lab, we look at the structured adoption of different practices. As previously mentioned both the User-centred and Participatory Strategies can be pursued adopting different practices. Leveraging on the conceptualization about "What people say", "Wat people do" and "What people make" previously introduced (Sanders, 2001 and 2006), we operationalize User-centred and Participatory Strategies as binary variables: User-centred (Participatory Strategy) is equal to 1 if the Living Lab adopts at least two out of three associated practices in a systematic way ( $4=$ Very often or $5=$ Always); otherwise it is equal to 0 . In 
this way we are able to capture both the breadth (quantity) and the depth (frequency) in the adoption of the two sets of practices. Time, Cost and Quality represent the most established dimensions in measuring the project success (Turner, 2009); for this reason the Project Performance outcomes are operationalized as the percentage of projects that have been completed with respect to the initial objectives in terms of time, cost and quality. In order to capture the impact generated by the projects developed by Living Labs, we operationalize the Transfer Performance as the percentage of completed projects that have generated services / products that have been commercialized in the market. As control variables, we collected data about the Geographic localization (country), Age (years) and Dimension (\# of employees) of each Living Lab. Finally, in order to verify the readability and clarity of the questionnaire we initially conducted five interviews by phone with Living Labs based in five different nations: Belgium, Finland, France, Italy and Portugal. The interviews allowed us to refine both questions and scales. The other 315 Living Labs were engaged by email and data were collected through a web-based questionnaire. Table 1 provides an overview of the collected data.

\begin{tabular}{lccccc}
\hline & N & Mean & Std. Dev. & Min & Max \\
\hline Living Lab details & & & & & \\
Age & 92 & 3.36 & 1.86 & 1 & 7 \\
Dimension & 83 & 6.46 & 7.23 & 1 & 40 \\
& & & & & \\
User-centred practices & & & & & \\
Observing users' behaviours & 92 & 2.93 & 1.23 & 1 & 5 \\
Capturing users' insights & 92 & 3.97 & 1.06 & 1 & 5 \\
Receiving users' feedbacks & 92 & 3.91 & 1.14 & 1 & 5 \\
User-centred Strategy & 92 & 0.82 & 0.39 & 0 & 1 \\
& & & & & \\
Participatory practices & & & & & \\
Co-designing with users & 92 & 3.55 & 1.18 & 1 & 5 \\
Collaborating with users through digital platforms & 92 & 3.08 & 1.16 & 1 & 5 \\
Enabling users' experience though prototypes & 92 & 2.19 & 1.18 & 1 & 5 \\
Participatory Strategy & 92 & 0.54 & 0.50 & 0 & 1 \\
& & & & & \\
Project Performances & & & & & \\
Time & 74 & $84.19 \%$ & $19.23 \%$ & $30.00 \%$ & $100.00 \%$ \\
Cost & 73 & $88.68 \%$ & $15.87 \%$ & $40.00 \%$ & $100.00 \%$ \\
Quality & 72 & $78.96 \%$ & $19.60 \%$ & $30.00 \%$ & $100.00 \%$
\end{tabular}




\section{Empirical Results}

According to the strategies adopted by the 92 Living Labs, it is possible to identify four clusters, as shown in Figure 3. Indeed, as described in the previous section, each living lab can adopt or not adopt (binary variable) an User-centred strategy and adopt or not adopt a Participatory Strategy (another binary variable). Almost half the sample $(44,57 \%)$ adopt both strategies, only 8 Living Labs $(8,70 \%)$ do not adopt any of the strategies analysed in this work. A great portion of the sample adopts the User-centred Strategy $(81.53 \%=44.57 \%+$ $36,96 \%)$, demonstrating how consolidated and well established it is in the practices managed by Living Labs, whereas 54.35\% of the Living Labs adopt the Participatory Strategy. The recent diffusion of the participatory approach is demonstrated by the fact that the youngest Living Labs are positioned in the upper half of the matrix. In particular, the nine Living Labs focusing on Participatory Strategy show peculiar characteristics: on average, they are the youngest ( 2.56 years) and the smallest ( 4.29 employees). For example the Forum Virium Helsinki is an innovation unit within the Helsinki City organization playing a key role in implementing Helsinki's Smart and Open City strategy. The main goal of Forum Virium Helsinki is to develop the essential building blocks for smart, and open cities of the future. They significantly rely on practices such as "Collaborating with users through digital platforms" and "Enabling users' experience though prototypes", while they focus less on "Observing users' behaviours" and "Capturing users' insights".

The 34 Living Labs focusing only on User-centered Strategy represent the oldest group (3.82 years). For examples Botnia Living Lab in Sweden is specialized in human-centric research and in the development of new ICT based solutions. Botnia Living Lab started in 2000 and has matured from a test-bed to a real-life experimentation environment. Today Botnia Living Lab is a world-leading environment for user-centred research, development and innovation, supported by methods, tools and experts in a variety of areas. Botnia Living Lab offers the development, evaluation and tests of new ICT-based ideas, concepts and prototypes with end-users independently and in situ. 
Finally the biggest group of Living Labs adopt both User-centered and Participatory strategies. For example the Spanish ErgoLab is a laboratory aiming at involving two specific actors such as citizens / users and SMEs in the current innovation scheme of the Basque Country.

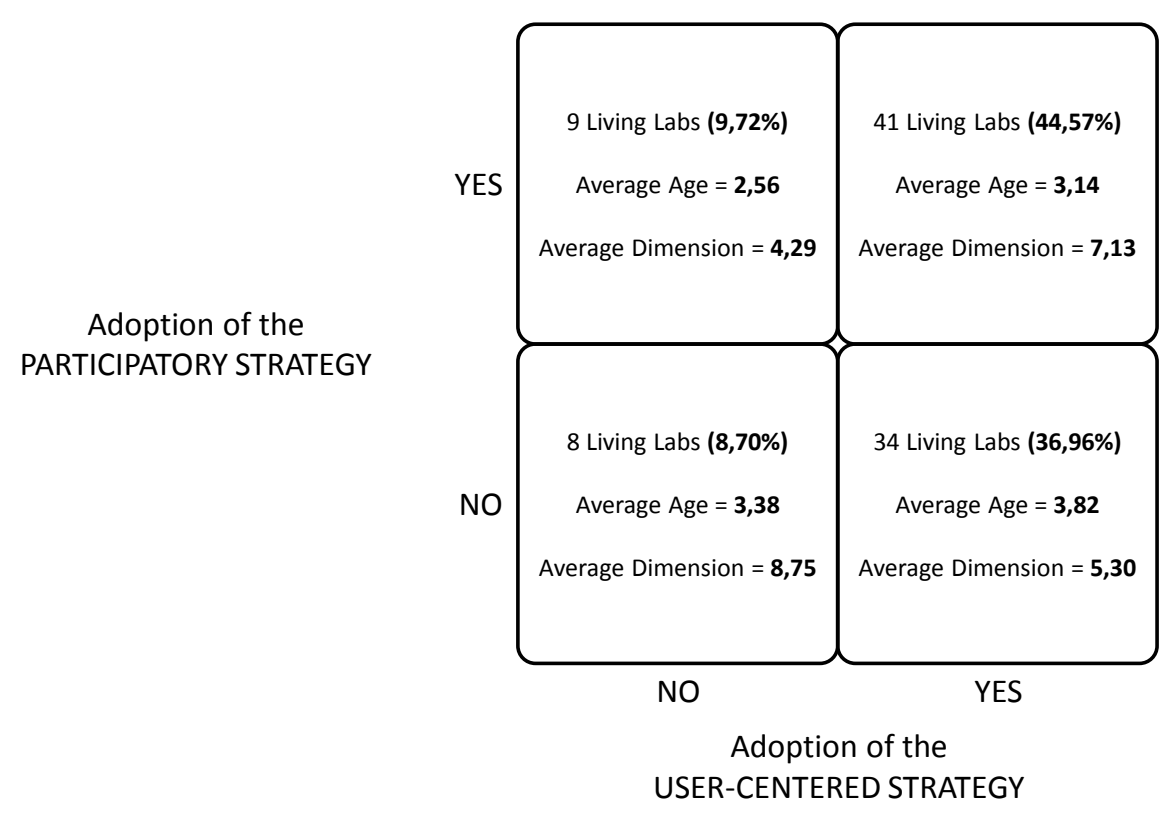

Figure 3: Number, age and dimension of Living Labs classified according to the adopted strategies

The adoption of the User-centred and Participatory Strategies influences both the Project and the Transfer Performance outcomes (see Figure 4). Whereas the Living Labs that focus on User-centred practices (bottomright quadrant) show the highest percentages about time and cost, the Living Labs that show the highest values of the Project Performance - Quality and the Transfer Performance - Go To Market, are those that merge both User-centred and Participatory practices (top-right quadrant). 


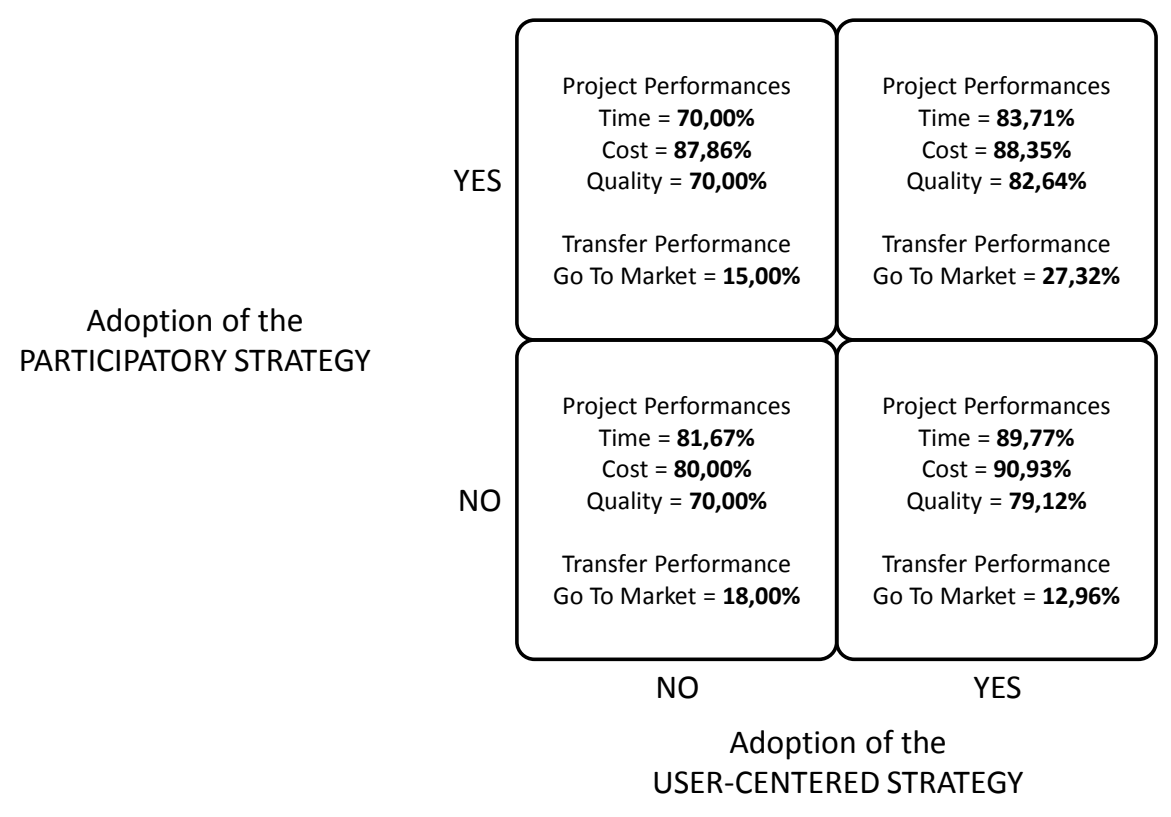

Figure 4: Project and Transfer Performance outcomes shown by the Living Labs classified according to the adopted strategies

To complement these results we used an ANOVA analysis to explore the different performance outcomes achieved by Living Labs that adopt different strategies. Whereas the Living Labs that adopt the User-centred Strategy show significantly higher values of the Project Performance - Time (see Table 2), those that adopt the Participatory Strategy show significantly higher values of the Transfer Performance - Go To Market (see Table 3).

\begin{tabular}{lccc}
\hline & $\begin{array}{c}\text { NON-ADOPTERS } \\
\text { of User-centred } \\
\text { Strategy }\end{array}$ & $\begin{array}{c}\text { ADOPTERS } \\
\text { of User-centred } \\
\text { Strategy }\end{array}$ & F \\
\hline Project Performances & & & $4.109 *$ \\
Time (74) & $75.00 \%(14)$ & $86.33 \%(60)$ & 0.958 \\
Cost (73) & $84.58 \%(12)$ & $89.49 \%(61)$ & 3.771 \\
Quality (72) & $70.00 \%(14)$ & $81.12 \%(58)$ & \\
Transfer Performance & & & \\
Go To Market (65) & $16.07 \%(14)$ & $20.84 \%(51)$ & 0.434 \\
\hline
\end{tabular}

$* \mathrm{p}<0.05 ; * * \mathrm{p}<0.01$

Table 2: Influence of User-centred Strategy on Project and Transfer Performance outcomes 
Even if only the Time performance shows a significant difference between non-adopters and adopters of the User-centred Strategy ( $86.33 \%$ vs $75.00 \%$ ), the second group of Living Labs is characterized by higher values of all performance outcomes. In other words, practices such as observing users' behaviours, capturing users' insights and receiving users' feedback positively impact innovation performance; more specifically, the Usercentred Strategy significantly impacts the efficiency of innovation projects, allowing them to conclude in time. One possible explanation may be associated with the interpretation of users' involvement as an accelerator of innovation projects; those Living Labs able to systematically involve users to observe them capture insights and receive feedback, are then able to avoid traditional problems in innovation projects that can cause delays: uncertainty, necessity of robust data, etc.

\begin{tabular}{lccc}
\hline & $\begin{array}{c}\text { NON-ADOPTERS } \\
\text { of Participatory } \\
\text { Strategy }\end{array}$ & $\begin{array}{c}\text { ADOPTERS } \\
\text { of Participatory } \\
\text { Strategy }\end{array}$ & F \\
\hline Project Performance & & & \\
Time (74) & $88.25 \%(32)$ & $81.10 \%(42)$ & 2.567 \\
Cost (73) & $89.22 \%(32)$ & $88.27 \%(41)$ & 0.064 \\
Quality (72) & $77.35 \%(31)$ & $80.17 \%(41)$ & 0.361 \\
& & & \\
Transfer Performance & & & \\
Go To Market (65) & $13.86 \%(28)$ & $24.32 \%(37)$ & $4.594^{*}$ \\
\hline * $p<0.05 ; *$ p $<0.01$ & &
\end{tabular}

Table 3: Influence of Participatory Strategy on Project and Transfer Performances

The comparison between non-adopters and adopters of the Participatory Strategy provides results that are more controversial. Only the Go To Market performance shows a significant difference: adopters of the Participatory Strategy show a significantly higher percentage of projects that are able to reach the market moving from the research stage to the innovation stage ( $24.32 \%$ vs $13.86 \%)$. In other words, the empirical results show how practices such as co-design, collaboration through digital platforms, and development of experience prototypes impact the effectiveness of innovation projects. As opposed to the adoption of Usercentred Strategy, the adoption of the Participatory Strategy highlights relevant trade-offs: if Quality and Go To Market performance outcomes are better in the case of adoption, adopters of the Participatory Strategy show the worst performance in terms of Time and Cost. One possible explanation may be associated with 
the trade-off between effectiveness and efficiency: systematic collaboration with users can allow achievement of better results in terms of quality and, consequently, marketability of the project outcome, thus reducing the efficiency of the innovation project in terms of time and cost.

\section{Discussion and Conclusions}

The advantages provided by innovation strategies based on collaboration with users have been demonstrated by several studies. Several researchers have already highlighted the shift from the usercentred approach (with the user as a subject) to a participatory one (with the user as a partner). Therefore, organizations and enterprises are looking for new methodologies to involve users in their innovation processes. The Living Lab methodology, defined as a design research methodology aimed at co-creating innovation through the involvement of aware users in a real-life setting, can provide new perspectives in the passage from User-Centred to Participatory Design. This paper, thanks to the answers received by 92 Living Labs belonging to the European Network of Living Labs i) investigated the strategies adopted by Living Labs in involving users in their innovation processes and ii) analysed the relationships between strategies and achieved innovation performance outcomes.

The strengthening and diffusion of the User-centred Strategy is demonstrated by the fact $81.52 \%$ of the interviewed Living Labs systematically adopt this approach, whereas only $54.35 \%$ state that they systematically apply participatory practices, such as co-design, collaboration through digital platforms, and development of experience prototypes. User-centred and Participatory strategies generate different impacts on innovation performances. The User-centred Strategy positively impacts all innovation performance outcomes (Time, Cost, Quality and Go To Market), but only the Time performance outcome shows a significant difference between non-adopters and adopters ( $86.33 \%$ vs $75.00 \%)$. Observing users' behaviours, capturing users' insights and receiving users' feedback positively impact the efficiency of innovation projects, thereby allowing them to be concluded in time. The Participatory Strategy shows that adopters are characterized by a significantly higher percentage of projects that are able to reach the market moving from the research stage to the innovation stage $(24.32 \%$ vs $13.86 \%)$. Practices such as co-design, collaboration 
through digital platforms, and development of experience prototypes allow the achievement of better results in terms of quality and, consequently, marketability of the project outcome, but reduce the efficiency of the innovation project in terms of time and cost. To some extents it seems that the users' participation can increase the project complexity to the point that projects become more articulated and difficult to manage in terms of time and cost, but it implies better quality and especially improves the capability to transform concepts in products.

These results have direct implications for Living Labs managers, that can consider the insights provided to improve their organizations, but there are also implications for policy makers interested in promoting innovation in their countries or regions. Indeed, to the best of our knowledge, this is the first quantitative study on the impact of Living Labs, and the positive results that we have found may suggest to policy makers to promote the birth of new Living Labs and the development of the existing ones. In particular, policy makers could direct their interventions towards the alignment of the Living Labs with regional and national innovation strategies, for instance in terms of sectors of technologies on which they have to focus in relation with cluster or smart specialisation strategies.

This study has some limits, which can also represent opportunities for further developments. Both main constructs can be significantly enriched: User Innovation Strategy and Innovation Performance are complex concepts that can benefit from the use of other indicators to complement the ones measured in this work. Furthermore both User-centred and Participatory practices can be better described by collecting additional data on the specific techniques adopted by Living Labs to observe users' behaviours, capture users' insights, receive users' feedback, co-design with users, etc. Similarly, Market and competitive performance achieved by products developed by Living Labs could be gathered to allow a more advanced and long term assessment of the strategies and practices adopted by Living Labs. Furthermore, the investigation about contextual factors, such as country, localization (urban vs rural), governance, etc., can support the identification of the different profiles of Living Labs.

The paper focuses on the strategies adopted by Living Labs; changing the unit of analysis from living labs to single projects developed by the living labs it will be possible to obtain additional insights. The analysis of the 
practices adopted by Living Labs in different projects can provide detailed and significant results about the relationships between practices and project / transfer performances.

Finally, as noted by Dell'Era and Landoni (2014), all Living Labs involve aware users in the co-creation process, but in some cases the participation is open to all potential users, while in other cases the users are preselected. This is a critical choice, because collaborative networks differ in the degree to which "membership" is open to anyone who wants to join (Pisano and Verganti, 2008). In open Living Labs there are no rules for who can join and who cannot join, and no one is vested with the authority to exclude someone, as opposed to closed Living Labs in which users are pre-selected and consequently invited to participate. Further analysis about the performances achieved by open and closed Living Labs can provide additional insights for the development of this methodology. 


\section{References}

- Almirall E and Wareham J. (2008). Living labs and open innovation: Roles and applicability. The Electronic Journal for Virtual Organizations and Networks, Vol. 10, Pp. 21-26.

- Almirall E. (2009). Understanding innovation as a collaborative, co-evolutionary process. Doctoral dissertation. Barcelona: Universitat Ramon Llull (URL). ESADE.

- Almirall E, Lee M and Wareham J. (2012). Mapping living labs in the landscape of innovation methodologies. Technology Innovation Management Review, Pp. 12-18.

- Bergvall-Kåreborn B and Ståhlbröst A. (2009). Living lab: an open and citizen-centric approach for innovation. Int. J. Innovation and regional development. Vol. 1 (No. 4), Pp. 356-370.

- Bogers M, Afuah A and Bastian B. (2010). Users as innovators: A review, critique, and future research directions. Journal of Management, Vol. 36(4), Pp. 857-875.

- Brown T (2008). Design Thinking. Harvard Business Review, Pp. 84-92.

- Brown T (2009). Change by Design: How Design Thinking Transforms Organizations and Inspires Innovation. HarperCollins.

- Buchanan R. (2001). Human dignity and human rights: Thoughts on the principles of human-centered design. Design issues, Vol. 17(3), Pp. 35-39.

- Chesbrough, H. W. (2003) Open Innovation: The New Imperative for Creating and Profiting from Technology. Boston: Harvard Business School Publishing.

- Chesbrough, H., and Bogers, M. (2014) Explicating Open Innovation: Clarifying an Emergin Paradigm for Understanding Innovation. In H. Chesbrough, W. Vanhaverbeke, \& J. West, New Frontiers in Open Innovation (p. 4-28). Oxford: Oxford University Press.

- Czyzewski P, Johnson J and Roberts E. (1990). Introduction: Purpose of PDC' 90. In A. Namioka and D. Schuler (eds.): $P D C^{\prime} 90$ Conference on Participatory Design, Seattle, Washington, March 31-April 1. Palo Alto, CA: Computer Professionals for Social Responsibility, Pp. ii-iii. 
- Dell'Era C and Landoni P. (2014). Living Lab: A Methodology between User-Centered Design and Participatory Design. Creativity and Innovation Management, Vol. 23, No. 2, Pp. 137-154.

- Følstad A. (2008). Living labs for innovation and development of communication technology: A literature review. The Electronic Journal for Virtual Organisations and Networks, Vol. 10, Pp. 99-131.

- Friess E. (2008). The user-centered design process: Novice designers' use of evidence in designing from data. PhD thesis, Carnegie Mellon University.

- Golini, R, Kalchschmid, M, Landoni, P (2015) “Adoption of project management practices: The impact on international development projects of non-governmental organizations" International Journal of Project Management 33, pp. 650-663

- Ibbs, C.W., Kwak, Y.H., 2000. Assessing project management maturity. Project Management Journal, vol. 31, Pp. 32-43.

- Karat J. (1996). User Centered Design: Quality or Quackery?. ACM/SIGCHI magazine, InteracGons july+august, Vol. 3, Issue 4, Pp. 18-20.

- Kelley T (2001). The Art of Innovation. New York: Curreny.

- Kotler P and Scott WG (1999). Marketing Management. Prentice Hall International, 7a ed.

- Knapp J (2016). Sprint - How to solve big problems and test new ideas in just five days. Google Ventures.

- Kviselius NZ., Andersson P, Ozan H and Edenius M. (2009). Living labs as tools for open innovation. Communications and Strategies, Vol. 74, Pp. 490-504 (2nd quarter).

- Leminen S, Westerlund M and Nyström AG. (2012). Living Labs as open innovation networks. Technology Innovation Management Review, Pp. 6-11.

- Liminen S, Nyström AG and Westerlund M (2015). A typology of creative consumers in living labs. Journal of Engineering and Technology Management, Vol. 37, Pp. 6-20.

- Lojacono G and Zaccai G (2004) The evolution of the Design-Inspired Enterprise. Sloan Management Review, Spring, 75-79. 
- Mao J, Vredenburg K, Smith PW and Carey T. (2005). The state of User-Centered Design practice. Communications of the ACM - The disappearing computer, Vol. 48, Issue 3, Pp. 105-109.

- Martin R (2009). The Design of Business: Why Design Thinking is the Next Competitive Advantage. Boston, MA: Harvard Business Press.

- Norman D. (1986). "Cognitive Engineering", in Norman D and Draper SW. (eds.), User Centered System Design: New perspectives on human-computer interaction, Pp. 31-61

- Norman D. (1988). The Design of Everyday Things. New York: Doubleday. ISBN: 0-385-26774-6.

- Nyström AG, Leminen S, Westerlund M and Kortelainen M. (2014). Actor role and role patterns influencing innovation in living labs. Industrial Marketing Management, Vol. 43, Pp. 483-495.

- Pascau C and van Lieshout M. (2009). User-led citizen innovation at the interface of services, info Vol. 11, issue 6, Pp. 82-96.

- Preece, J. (1993). A Guide to Usability. Addison-Wesley Longman Publishing Co., Inc. Boston, MA, USA. ISBN:020162768X.

- Riedl C, Böhmann T, Rosemann M and Krcmar H. (2009). Quality management in service ecosystems. Information Systems and e-Business Management, Vol. 7(2), Pp. 199-221.

- Robinson K.C. (1998). An examination of the influence of industry structure on eight alternative measures of new venture performance for high potential independent new ventures. Journal of Business Venturing, Vol. 14, Pp. 165-187

- Sanders EB-N. (2000). Generative tools for Co-designing. In proceedings of Collaborative Design CoDesigning 2000, Scrivener, Ball and Woodcock (Eds.) London: Springer-Verlag, Pp. 3-12.

- Sanders EB (2001). Virtuosos of the experience domain. In 2001 IDSA Education Conference.

- Sanders EB-N. (2002). From user-centered to participatory design approaches. Design and the social sciences: Making connections, Pp. 1-8.

- Sanders EB-N. (2006). Design Research in 2006. Design Research Quarterly, V.1:1, Design Research Society. ISSN 1752-8445. 
- Sanders EB-N and Stappers PJ. (2008). Co-creation and the new landscapes of design. CoDesign: International Journal of CoCreation in Design and the Arts, 4, Pp. 5-18.

- Sanders EB-N, Brandt E and Binder T. (2010). A Framework for Organizing the Tools and Techniques of Participatory Design. PDC 10 Proceedings of the 11th Biennial Participatory Design Conference, Sydney, Australia, Pp. 195-198.

- Schuler D and Namioka A. (1993). Participatory Design: Principles and Practices. Hillsdale: Lawrence Earlbaum Associates, NJ, USA. ISBN:0805809511

- Schuler D and Namioka A. (1993). Participatory Design: Issues and concerns. Computer Supported Cooperative Work 7, Pp. 167-185.

- Schuurman D, De Moor K, De Marez L and Evens T. (2011). Living Lab research approach for mobile TV. Telematics and Informatics, Vol. 28, Pp. 271-282.

- Sleeswijk Visser F, Van der Lugt R and Stappers PJ. (2005) Participatory Design needs participatory communication: New tools for sharing user insights in the product innovation process. Proceedings of the 9th European Conference on Creativity and Innovation, Lodz, Poland, Pp. 173-195.

- Sleeswijk Visser F, Stappers PJ, Van der Lugt R and Sanders L. (2005). Contextmapping; experiences from practice. CoDesign: International Journal of CoCreation in Design and Arts, 1(2) Pp. 119-149.

- Slocum N. (2003). Participatory methods toolkit: a practitioner's manual. King Baudouin Foundation, the Flemish institute for science and technology and UNU/CRIS. ISBN 90-5130-447-1.

- Spencer D. (2009). Card Sorting: Designing Usable Categories. Rosenfeld media. ISBN 1933820020

- Spradley JP (1979). The ethnographic interview. Harcourt Brace Jovanovich College Publishers, Orlando, FL.

- Tang T, Wu Z, Hamalainen M and Ji Y (2012). From Web 2.0 to Living Lab: an Exploration of the Evolved Innovation Principles. Journal of Emerging Technologies in Web Intelligence, Vol. 4, No. 4, Pp. 379-385.

- Turner JD (2009). The Handbook of Project-Based Management - Leading Strategic Change in Organizations ( $3^{\text {rd }}$ Edition). McGraw-Hill, United States of America. 
- Van Looy B., Landoni, P., Callaert J., Van Pottelsberghe B., Sapsalis E., Debackere K., (2011) "Entrepreneurial Effectiveness of European Universities: An empirical assessment of antecedents and trade-offs" Research Policy, Vol. 40, pp. 553-564

- Von Hippel E (1986). Lead Users: A source of novel product concepts. Management Science, Vol. 32, No. 7, Pp. 791.

- Westerlund M and Leminen S. (2011). Managing the challenges of becoming an open innovation company: Experiences from Living Labs. Technology Innovation Management Review, Pp. 19-25. 